Elena Díaz Silva

Aribert Reimann

Randal Sheppard (eds.)

Horizontes del exilio

Nuevas aproximaciones a la experiencia de los exilios entre Europa y América Latina durante el siglo xx 


\section{Ediciones de Iberoamericana}

101

Consejo editorial:

Mechthild Albert

Rheinische Friedrich-Wilhelms-Universität, Bonn

Enrique García-Santo Tomás

University of Michigan, Ann Arbor

Aníbal González

Yale University, New Haven

Klaus Meyer-Minnemann

Universität Hamburg

Daniel Nemrava

Palacky University, Olomouc

Katharina Niemeyer

Universität zu Köln

Emilio Peral Vega

Universidad Complutense de Madrid

Janett Reinstädler

Universität des Saarlandes, Saarbrücken

Roland Spiller

Johann Wolfgang Goethe-Universität, Frankfurt am Main 


\section{Horizontes del exilio}

\section{Nuevas aproximaciones a la experiencia de los exilios entre Europa y América Latina durante el siglo Xx}

Elena Díaz Silva

Aribert Reimann

Randal Sheppard (eds.) 


\section{ÍNDICE}

Presentación

Elena Díaz Silva, Aribert Reimann y Randal Sheppard

\section{REDEs transContinentales}

Pablo Yankelevich

Exilios: México en la memoria latinoamericana . . . . . . . . . . . . . . . . .

Aurelio Velázquez Hernández

Las redes panamericanas de ayuda al exilio republicano español . . . . . . . . . .

Olga Glondys

El europeismo y los exilios (1939-1945): pretexto para unas reflexiones acerca

Randal Sheppard

El exilio y la politica transnacional en el diseño de Clara Porset . . . . . . . . . . .

\section{ENCUENTROS TRANSNACIONALES}

Diego Gaspar Celaya

Exiliados españoles en el esfuerzo de guerra francés, 1939-1940 . . . . . . . . . .

Jorge de Hoyos Puente

Simpatías y antipatías de los exiliados republicanos en México. Discursos politicos y prácticas sociales...

Andrea Acle-Kreysing

El exilio antifascista de habla alemana en México durante la Segunda Guerra

Mundial: una peculiar adopción del mito de la Revolución Mexicana.... . 


\section{Contextos urbanos}

Aribert Reimann

Distrito transnacional. Espacios urbanos del exilio político en el Distrito Federal

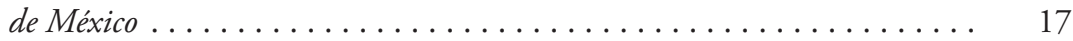

Víctor M. Macías-González

Otros camaradas de ruta. Las colaboraciones transnacionales de los editores republicanos españoles y los activistas homófilos norteamericanos en Ciudad de México, c. 1940-1960 . ........................

Bárbara Ortuño Martínez

El exilio republicano en Argentina (1936-1975). Avances, retrocesos y nuevas

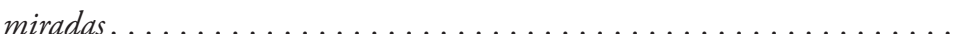

IV. IDENTIDADES NARRATIVAS

Guadalupe Adámez Castro

“Todo ser humano no ha muerto”. Súplicas y peticiones del exilio español (1939-1945).

María Zozaya-Montes

Sentimientos prisioneros del exilio. Contradicción burguesa entre las obligaciones públicas y las emociones privadas del intelectual Antonio Zozaya, 1939-1943

Elena Díaz Silva

Las heterodoxias del exilio: Emilio Prados a través de su correspondencia . . . . . .

Pilar Domínguez Prats

"El pasado ya no interesa a nadie". Las memorias del exilio en el contexto de la transición democrática, Cecilia Guilarte

LOS AUTORES 


\title{
SENTIMIENTOS PRISIONEROS DEL EXILIO. CONTRADICCIÓN BURGUESA ENTRE LAS OBLIGACIONES PÚBLICAS Y LAS EMOCIONES PRIVADAS DEL INTELECTUAL ANTONIO ZOZAYA, 1939-1943
}

\author{
María ZoZaYA-Montes
}

A Juan y Christian Zozaya Stabell-Hansen, in memoriam

\author{
Toda la familia del valiente era republicana, \\ y don Vicente Blasco Ibáńez, Dios; \\ y Lerroux su representante en la tierra, \\ y Azatti, Castrovido y Zozaya, sus profetas \\ Max Aub, Las buenas intenciones, 1954.
}

"Adiós tierra Que te alejas". El discurso de Zozaya cataliza SENTIMIENTOS PÚBLICOS

En 1939 el Sinaia embarcaba en Francia repleto de exiliados con destino incierto en México, lejos de los ataques fascistas que dominaban España. Cuando pasaba por el estrecho de Gibraltar, Antonio Zozaya daba el discurso de despedida desde la popa del barco. "Es la primera vez que se reunía en cubierta todo el pasaje", recreaba Andrés Trapiello, ${ }^{2}$ cientos de refugiados

${ }^{1}$ María Zozaya-Montes realiza su investigación con la beca FCT posdoctoral SFRH/ BPD/91130/2012, en el CIDEHUS-UÉ, con los fondos: UID/HIS/00057/2013; POCI-010145-FEDER-007702.

${ }^{2}$ Trapiello (1998), pp. 228-229. 
escuchaban apiñados, "a punto de echar a pique con su propio peso un viejo y destartalado buque de hierro". ${ }^{3}$ Una foto publicada por la revista americana Life permite recrear la escena. ${ }^{4}$ Un bosque de cabezas creyentes en la democracia escuchaba con silencio sepulcral el discurso que Zozaya dirigía con un hilo de voz y "la vista clavada en la tierra que se aleja". "Ya doblado su cuerpo por el peso de los ańos", 5 aquel anciano reputado por su defensa de los derechos y la igualdad recordaba la injusticia en su discurso ${ }^{6}$ Con sus palabras dedicadas a esa "patria amada que se aleja, que [...] solloza bajo el yugo opresor", consiguió catalizar los sueños de los asilados. Definía la esperanza de ver aquella tierra liberada, donde los españoles armonizasen en fraternidad: “¿Cuántos podrán encontrarla redenta, emancipada, gozando de las aventuras de una verdadera democracia, en que todos los hombres sean hermanos y en que todos comulguen con las ideas de paz, de progreso y libertad?" ?

Los sentimientos de la multitud quedaban encerrados en el puño que muchos levantaron como símbolo político de su resistencia. ${ }^{8}$ La memoria de algunos exiliados -compendiada por Sánchez Vázquez-iba a congelar aquel momento en el cual, "sin que se deshiciera un nudo en nuestra garganta", "vimos perderse en la lejanía la tierra de España", "cuando aún resonaba en nuestros oídos", "esta última exclamación de don Antonio: jAdiós, patria que te alejas, adiós! Un recuerdo imborrable me acompañará toda la vida". ${ }^{9}$ Incluso la literatura posterior iba a consagrar la imagen del honorable republicano de barba blanca que "no tenía fuerzas ni para hablar, pero hizo llorar a más de la mitad del pasaje, y muchos no lloraron por la vergüenza, hombría, y

\footnotetext{
${ }^{3}$ Trapiello (2000).

${ }^{4}$ Hamilton Fish Armstrong, "Spanish Army in France ", en Life (17 de julio de 1939), pp. 64-69, <http://bit.ly/2guoWhx>.

5 Sánchez Vázquez (1989), pp. 10-11, y (1997), pp. 23-24.

${ }^{6}$ Zozaya (1939a), en Sánchez Vázquez (1989).

${ }^{7}$ Zozaya (1939a).

${ }^{8}$ Sobre el empleo del símbolo comunista del puño en alto, además de representar el "no pasarán”, recuerda que muchos refugiados tenían hasta tres carnets de partido, y que la gran mayoría fue obligada a hacerse comunista por miedo a los fusilamientos rusos (lo que en la Europa filodictatorial dio la imagen de que el barco iba cargado de bolcheviques); Trapiello (2000).

9 Sánchez Vázquez (1989), p. 11.
} 
el instinto protector de cabeza de familia. En otras palabras: actuó de forma patriarcal coherente, pues la defensa de la institución familiar burguesa le hizo ocultar sus sentimientos de dolor.

Como narraron los principales periódicos, cuando Antonio falleció en 1943 en la capital, a su sepelio asistieron multitudes de personas, las autoridades republicanas en el exilio y las de México, encabezadas por Lázaro Cárdenas. Una muerte cercana que por su vejez él ya pudo intuir, y que probablemente influyó para su consideración de mantener en privado sus sentimientos de dolor. Aquellas predicciones sobre la importancia de su figura que podría dañar con su sombra (caso de haber publicitado una relación negativa) pueden intuirse al leer los comentarios de las necrológicas o de los artículos recordando su figura. En todos abundó el campo semántico vinculado al "gran intelectual", "maestro", "ejemplo de escritores" y más collares de letras ilustres sobre la grandiosidad del maestro. ${ }^{99}$ Su propio hijo Juan refrendaba indirectamente la importancia de que aquel anciano padre le hubiese protegido, al escribir a su hermano Carlos:

Pero sí te diré que en medio de todo ha sido un gran consuelo el grandioso homenaje que fue el entierro. No pudo ser más emocionante ni nunca en México fue tanta gente como al de papá. No faltó nadie. Ya te daré el detalle de nombres y de coronas. Los niños del colegio Madrid desfilaron ante la tumba y fueron llenándola de flores rojas, amarillas y moradas hasta formar la bandera republicana... ${ }^{100}$

\section{CONCLUSIONES: CONTRASTE DEL PERSONAJE PÚBLICO ANTE EL DILEMA PRIVADO}

En este estudio planteamos la disyuntiva entre los problemas privados y la proyección pública gracias a fuentes epistolares inéditas. Abordamos

su hijo). El fenómeno en sociología se ha definido como la extensión de las redes de amistad por la confianza, en vulgata: "los amigos de mis amigos son mis amigos", Pontieux (2006). La importancia de movilizar tales redes luego traducidas en apoyos y bienes intangibles, en Zozaya (2007), pp. 13-28.

99 Enrique Díez Canedo, "Necrológica”, en América (10 de febrero de 1943), pp. 31-32.

${ }^{100}$ AFZS-H: n. ${ }^{o} 13$ (México, 1 de febrero de 1943). 
detalles desconocidos del exilio, de la estancia infrahumana de los refugiados en Francia, de la incertidumbre y complicaciones que afectaron a miles de personas buscando una salida de emergencia tras la guerra, factores que suelen perderse de vista cuando se traza un discurso histórico lineal cuyo trayecto directo era Francia, el Sinaia y Ciudad de México. Mostramos una perspectiva subjetiva de Antonio Zozaya. Tratamos la experiencia del exilio a partir de la biografía de un hombre con representación pública. Reflejamos la contradicción de un notable que siempre luchó por las libertades, pero, sin embargo, no sacó a la luz las injusticias que sentía en el plano privado. Damos relevancia a la faceta pública del personaje porque consideramos que la disyuntiva a la cual se enfrenta al llegar al exilio fue generada previamente por la fama que le precedió. Intentamos mostrar los elementos que le convirtieron en un intelectual destacado, con las campañas o escritos que le destacaron como prohombre luchador contra las desigualdades, y cómo esa imagen construida en el ámbito público desaparece en la realidad cotidiana del ámbito privado.

Este personaje mantiene unos valores propios de la burguesía acomodada del XIX, aun cuando en su faceta de intelectual se vinculaba a la renovación del siglo xx. Siguiendo el ideal burgués, iba a negar otro que se estaba imponiendo en la esfera pública desde 1900, el de la libertad y la tendencia librepensadora que él tanto iba a defender como krausista e institucionista. Pese a convertirse en uno de los adalides de los nuevos patrones de la libertad en la esfera pública, no pudo escapar del corsé del romanticismo burgués patriarcal en que se había criado. Cuando Antonio Zozaya tuvo que tomar una decisión se convirtió más en el paterfamilias burgués -dependiente de la esfera pública- que en el representante de aquel librepensador que siempre había luchado por la justicia, sin defender la suya. Intentando proteger a su hijo, conocedor de los mecanismos que activaban solidaridades, siguió la lógica burguesa. Mantuvo la paz y los ideales familiares, movilizándose en función de los sentimientos aprendidos, ligados a un rol masculino de cabeza de familia. Su actuación manifiesta el contraste entre individuo y sociedad: refleja las experiencias individuales ocultas frente a la memoria colectiva del exilio, homogénea y protectora del orden burgués, amparada en el espejo público. 


\section{Archivos}

Archivo General de la Administración (AGA, Alcalá de Henares)

Archivo General de la Nación (Ciudad de México)

Fundación Pablo Iglesias (AHFPI, Alcalá de Henares)

Centro Documental de la Memoria Histórica (CDMH, Salamanca)

Archivo Familiar Zozaya Stabell-Hansen (AFZS-H)

\section{Periódicos}

América

Excélsior

Hoy

Life

Sinaia. Diario de la primera expedición de republicanos españoles a México El Tiempo

\section{Textos por Antonio Zozaya}

Zozaya, Antonio (1927): Ideogramas, homenaje de sus lectores. Madrid: Sociedad Española de Librería.

- (1939a): “Pero tu, España, resurgirás!”, en Sinaia. Diario de la primera expedición de republicanos españoles a México, n. ${ }^{\circ} 2$ (27 de mayo), p. 2.

- (1939b): "Al cumplir sus 80 años. Unas manifestaciones de Antonio Zozaya”, en Sinaia. Diario de de la primera expedición de republicanos españoles a México, n. ${ }^{\circ}$ 9 (3 de junio), p. 3.

\section{BiBLIOGRAFÍA}

Abellán, José Luis (ed.) (1977): El exilio español de 1939, tomo IV. Madrid: Taurus. Álvarez Junco, José (1900): El Emperador del Paralelo, Alejandro Lerroux. Madrid: Alianza.

Aub, Max (1986 [1954]): Las buenas intenciones. Madrid: Alianza.

Aznar Soler, Manuel (I988): "Cultura y literatura del exilio republicano español de 1939 en México", en Taifa 4. Monográfico sobre el exilio español en México (1939-1977), pp. 15-29. 
Burdiel, Isabel (1996): Mary Woolstonecraft, Frankenstein o el moderno Prometeo. Madrid: Cátedra.

- (2004): Isabel II, no se puede reinar inocentemente. Madrid: Espasa.

Burdiel, Isabel y J. Colin Davies (2005): El otro, el mismo, Biografía y Autobiografía en Europa (siglos XVII-XIX). Valencia: Universitat de València.

Conte, Rafael (1970): "Un fenómeno individual”, en Narraciones de la España desterrada. Antología de Rafael Conte. Barcelona: EDHASA, pp. 13-16.

Esplá, Carlos (2000): “Sobre la llamada inmigración política espańola”, en Migraciones \& Exilios, n. ${ }^{\circ}$ 1, pp. 211-214.

Frevert, Ute (2010): Emotions in History, Lost and Found. Budapest: Central European University Press.

Gutiérrez, Ángel (1995): “Lázaro Cárdenas y el Estado Mexicano, 1934-1940”, en TzinTzun, n. ${ }^{\circ}$ 21, pp. 61-81.

Holroyd, Michael (2009): "Changing fashions in biography", en The Guardian (7 de noviembre).

Jofresa, Silvia y Carlos Álvarez Ramiro (1997): "La narrativa del Exilio español en México”, en Taifa, n. ${ }^{\circ}$ 4, pp. 73-76.

Melgar, Ricardo (2003): Redes e imaginario del exilio en México y América Latina, 1934-1949. Buenos Aires: Libros en Red.

Otero Urtaza, Eugenio (2001): "Las relaciones de amistad entre los krausitas", en Fernando de Castro y su legado intelectual. Madrid: Fundación Fernando de Castro, pp. 123-154.

Pellistrandi, Benoît y Jean-François Sirinelli (eds.) (2008): L'Histoire culturelle en France et en Espagne. Madrid: Casa de Velázquez.

Pérez Ledesma, Manuel (1987): El obrero consciente. Madrid: Alianza.

Pérez Ledesma, Manuel e Isabel Burdiel (eds.) (2008): Liberales eminentes. Madrid: Marcial Pons.

Pons, Anaclet y Justo Serna (2005): La historia cultural. Madrid: Akal.

Pontieux, Sophie (2006): Le capital social. Paris: La Découverte.

Reddy, William M. (1999): "Emotional Liberty: Politics and History in the Antropology of Emotions", en Cultural Antropology, n. ${ }^{\circ} 14$ (2), pp. 256-288.

Requena SAntos, Félix (1994): Amigos y redes sociales: elementos para una sociología de la amistad. Madrid: Siglo XXI de España Editores.

Rodríguez López, Carolina y Daniel Ventura Herranz (2014): “De exilios y emociones", en Cuadernos de Historia Contemporánea, vol. 36, pp. 113-138.

Rosewein, Barbara H. (2010): "Problems and Methods in the History of Emotions", en Passions in Context, n. ${ }^{\circ} 1$ (I), pp. 1-32.

Sánchez Albornoz, Nicolás (ed.) (1991): El destierro español en América: un trasvase cultural. Madrid: Instituto de Cooperación Iberoamericana. 
SÁnchez VÁzquez, Adolfo (ed.) (1989): Siania. Diario de la primera expedición de republicanos a México (ed. Facsímil). Ciudad de México: Universidad Autónoma Metropolitana/La Oca.

- (1997): Del exilio en México: recuerdos y reflexiones. Ciudad de México: Grijalbo.

Savigneau, Josayne (1995): Margarite Youcenar. La invención de una vida. Madrid: Alfaguara.

Serna, Justo (2010): "Literatura del yo", en Mercurio. Los géneros autobiográficos, n. ${ }^{\circ}$ 122, pp. 5-9.

Souto Alabarce, Arturo (1982): "Letras, Ensayo, Pintura, Música y Danza", en Salvador Reyes Nevares (coord.), El exilio español en México, 1939-1982. Ciudad de México: Fondo de Cultura Económica/Salvat, pp. 363-493.

Taddeo, Julie A. (2002): Lytton Strachey and the Search for Modern Sexual Identity. London: Routlegde.

TAmir, Maya (2011): “The Maturing Field of Emotion Regulation”, en Emotion Review. Emotion Regulation, vol. 3, n. ${ }^{\circ}$ 1, pp. 3-7.

Trapiello, Andrés (1998): Dias y Noches. Madrid: Espasa.

- (2000): "La Odisea del Sinaía", en El Pais (8 de agosto).

UCElay da Cal, Margarita (1951): Los españoles pintados por si mismos. Ciudad de México: El Colegio de México.

Zozaya-Montes, María (2000): "Trayectoria de un intelectual olvidado: Antonio Zozaya y You”, en Jaime Ferrán, n. 19 (mayo), pp. 205-226.

- (2007): Del ocio al Negocio, redes y capital social en el Casino de Madrid. Madrid: La Catarata.

Zozaya-Montes, María y Leonor Zozaya-Montes (2016): "La difusión cultural mediante la traducción: la Biblioteca Económico Filosófica de Antonio Zozaya y You”, en Francisco Lafarga y Luis Pegenaute (eds.), Autores traductores en la España del siglo XIX. Kassel: Reichenberger, pp. 531-551. 
Jorge de Hoyos Puente. Licenciado y doctor por la Universidad de Cantabria. Ha sido Visiting Scholar en la Universidad de Columbia en Nueva York y en el Centro de Estudios Históricos de El Colegio de México en 2012 y 2013. Desde 2014 trabaja en el Departamento de Historia Contemporánea en la UNED. Desde 2015 es secretario general del Centro de Estudios de Migraciones y Exilios de la UNED (CEME). Es autor de dos libros, $\mathrm{La}$ utopía del regreso (2012) y Viva la inteligencia (2016), editor de dos libros, así como autor de más de cuarenta contribuciones en revistas indexadas y libros colectivos. Ha sido ponente invitado en más de cuarenta encuentros científicos internacionales en Estados Unidos, México, Argentina, Chile, Uruguay, Francia, Portugal y España, así como profesor invitado en las universidades de Aguascalientes (México), La Plata (Argentina) y la MGIMO (Rusia).

Víctor M. Macías-González. Doctor en historia latinoamericana por la Texas Christian University (1999) y profesor de la University of WisconsinLa Crosse (2000). Especializado en el estudio de las élites hispanoamericanas del siglo XIx (1750-1930), ha publicado numerosos estudios sobre exilio, género, masculinidad y homosexualidad. Ha recibido destacados reconocimientos a su amplia labor, como el Equity Prize de The American Historical Association (2015), y el LGBT Studies Research Fellowship, de Yale University (2014-2015). Ha publicado Masculinity and Sexuality in Modern Mexico (2012).

Bárbara Ortuño Martínez. Doctora en Historia por la Universidad de Alicante. Ha sido becaria posdoctoral de CONICET en la Universidad Nacional de Mar del Plata. En la actualidad está vinculada al Instituto Universitario de Investigación de Estudios de Género de la Universidad de Alicante. Forma parte del proyecto de investigación "Género, compromiso y trasgresión en España, 1890-2015”, dirigido por Mónica Moreno y financiado por el Ministerio de Economía y Competitividad de España (FEM201676675-P). Sus líneas de investigación transitan la interacción de las diversas oleadas migratorias en los lugares de destino y el papel de las mujeres y la infancia dentro de los movimientos migratorios, entre otros. A través de las segundas generaciones está avanzando sobre el exilio argentino de los años setenta en Espańa desde la perspectiva de género. Ha participado en nume- 
rosos congresos nacionales e internacionales y ha publicado sus trabajos en revistas académicas de reconocido prestigio como Ayer, Storia delle Donne o Historia Social. A lo largo de este año verá la luz su libro Hacia el hondo bajo fondo... Inmigrantes y exiliados en la capital de Argentina tras la Guerra Civil española (en prensa).

Aribert Reimann. Licenciado y doctor por la Universidad de Tübingen (2000). Asistente académico y habilitado por la Universidad de Colonia (2009). Entre 2008 y 2013 ha sido lector y tutor en historia europea moderna a Wadham College (University of Oxford). Desde 2013 es investigador principal del proyecto de investigación "Left-wing Exile in Mexico, 1934-1960" situado en el Instituto de Historia Ibérica y Latinoamericana de la Universidad de Colonia y financiado por el European Research Council (ERC). Es autor de publicaciones sobre la historia social y cultural de la Primera Guerra Mundial (Der große Krieg der Sprachen. Untersuchungen zur historischen Semantik in Deutschland und England zur Zeit des Ersten Weltkriegs, 2000), la historia cultural y social de protestas políticos y estudiantiles durante los años sesenta (Dieter Kunzelmann: Avantgardist, Protestler, Radikaler, 2009) y la historia transnacional del exilio político en Ciudad de México durante los años cuarenta y cincuenta.

Randal Sheppard. Doctor en Historia por la Universidad de La Trobe, en Melbourne. En la actualidad es profesor de Historia y Estudios Internacionales en la Universidad de Leiden. Entre 2013 y 2016 trabajó como investigador contratado por la Universidad de Colonia, suscrito al proyecto financiado por el European Research Council titulado "Left-wing Exile in Mexico (1934-1960)". Es autor del libro A Persistent Revolution: History, Nationalism, and Politics in Mexico Since 1968 (2016). Ha presentado su investigación en numerosos congresos y foros académicos en Australia, Estados Unidos, América Latina y Europa, y ha publicado sus trabajos sobre la historia mexicana contemporánea en revistas académicas como Latin American Research Review, Nations and Nationalism y The Americas.

Aurelio Velázquez Hernández. Doctor en Historia por la Universidad de Salamanca y actualmente investigador en el Departamento de Historia Con- 
temporánea de la Universidad Nacional de Educación a Distancia (UNED). Ha sido investigador visitante en la Universidad Nacional Autónoma de México y ha realizado estancias cortas de investigación en varios países. Sus investigaciones se han centrado en la Historia del exilio republicano español en América Latina. Es especialista en el estudio de los organismos de ayuda a los españoles, y las redes internacionales de solidaridad con este exilio. Es autor de varias publicaciones entre las que destaca la monografía titulada Empresas y finanzas del exilio. Los organismos de ayuda a los Republicanos españoles en México (1939-1949) (2014).

Pablo Yankelevich. Doctor en Estudios Latinoamericanos y profesor investigador del Centro de Estudios Históricos de El Colegio de México. Entre sus últimos libros destacan: Raza y politica en Hispanoamérica (en colaboración con Tomás Pérez Vejo, 2017); Inmigración y racismo: contribuciones a la historia de los extranjeros en México (2015); ¿Deseables o inconvenientes? Las fronteras de la extranjería en el México posrevolucionario (2011); Ráfagas de un exilio. Argentinos en México, 1974-1983 (2010); Nación y extranjería: la exclusión racial en las politicas migratorias de Argentina, Brasil, Cuba y México (2009); y Argentina, 1976: estudios en torno al golpe de Estado (en colaboración con Clara E. Lida y Horacio Crespo, 2008).

María Zozaya-Montes. Doctor Europeus en Historia por la Universidad Complutense de Madrid, donde obtuvo los premios Extraordinario de Licenciatura (UCM, 1999) y Extraordinario de Doctorado (UCM, 2009). Realizó su tesis doctoral en el CSIC con las becas de Iniciación a la Investigación, FPI, I3P y Caja Madrid. Obtuvo un contrato Juan de la Cierva en la Universidad de Valladolid, Departamento de Historia Contemporánea. Se ha especializado en élites y espacios de sociabilidad en el siglo XIX y XX. Disfruta de una beca posdoctoral de la FCT portuguesa en el CIDEHUS, Universidad de Évora. Ha recibido los premios de Historia: Real Maestranza de Caballería de Ronda (RMR, 1999), de Investigación de la Asociación de Historia Social (AHS, 2007) y de Investigación Municipal "Antonio Maura" (PVM, 2008). Ha escrito los libros El Casino de Madrid, orígenes y primera andadura (2002), Del ocio al negocio, redes y capital social en el Casino de Madrid, 1836-1900 (2007), Viaje y prisión del ingeniero militar José Ma- 
ría Román durante la Guerra de la Independencia, 1808-1814 (2008), Ocio, sociabilidad y representación social (2009), e Identidades en juego, formas de representación social del poder de la élite en un espacio de sociabilidad masculino, 1836-1936 (2016). 